\title{
Radiooncological Aspects Regarding Multimodal Primary Treatment of Breast Cancer - a Review
}

\author{
Rainer Souchon $^{\mathrm{a}}$ Wilfried Budach ${ }^{\mathrm{b}}$ Johannes Claßen ${ }^{\mathrm{c}}$ \\ a Department of Radiation Oncology, AKH Hagen gGmbH, \\ ${ }^{b}$ Department of Radiation Oncology, University Hospital, Düsseldorf, \\ c Department of Radiation Oncology, St. Vincentius Kliniken, Karlsruhe, Germany
}

\section{Key Words}

Breast cancer, local-regional · Radiation therapy: adjuvant Systemic treatment . Oncoplastic surgery

\section{Summary}

Locoregional percutaneous radiation therapy (RT) is an integral part of a multimodal curative therapeutic concept in non-invasive and locally-limited invasive breast cancer. Large prospective randomized clinical trials and recent meta-analyses have demonstrated that RT is a major independent prognostic factor with a positive influence on local and locoregional tumor control after mastectomy and after breast-conserving surgery (BCS). RT improves local and locoregional control, independent of systemic antineoplastic therapy. Local recurrence rate is reduced by two thirds, the overall long-term reduction of local recurrence measures $>20 \%$. Rate of survival and quality of life are improved by this increased rate of tumor control. Depending upon the primary stage and related to an interval of 20 years, significant improvements achieved by RT range between $5-10 \%$. After breast-conserving surgery, RT improves the prognosis, and long-term results are equal to those after mastectomy. Application of a total dose of 50-50.4 Gy in 1.8-2.0 Gy fractions, 5 times per week, is the considered standard therapy for irradiation of whole breast after BCS, chest wall or locoregional lymphatics, respectively. Delivery of fewer, larger fractions, reduction of target volume for RT after BCS as well as different intra- and postoperative radiation techniques (brachytherapy, electron beams and others) or more precise definition of patients who might benefit from different locoregional lymph node irradiation are currently in the focus of radiooncological investigations regarding primary treatment of breast cancer patients. Current topics concerning the application of RT are possible interactions with potentially cardiotoxic systemically administered antineoplastic drugs, questions of sequence of therapies thereby as well as the combination with oncoplastic surgery. These aspects and further developments in RT of breast cancer will be described in detail in this article.

\section{Schlüsselwörter}

Mammakarzinom, lokoregional begrenzt · Radiotherapie: adjuvant . Systemische Therapie · Onkoplastische Operationen

\section{Zusammenfassung}

Beim nichtinvasiven und beim lokal begrenzten invasiven Mammakarzinom ist die lokoregionale perkutane Strahlentherapie integraler Bestandteil eines kurativ ausgerichteten multimodalen Therapiekonzeptes. Große prospektive und randomisierte klinische Studien und aktuelle Metaanalysen bestätigen die Radiotherapie (RT) als einen bedeutenden unabhängigen Prognosefaktor mit positivem Einfluss auf die lokale und lokoregionale Tumorkontrolle sowohl nach brusterhaltender Operation (BCS) als auch nach Mastektomie. Die RT verbessert unabhängig von einer systemischen antineoplastischen Therapie die lokale und lokoregionale Kontrolle. Sie senkt die Lokalrezidivrate um zwei Drittel. Langfristig resultiert daraus eine absolute Reduktion der Lokalrezidivrate um $>20 \%$. Durch die Steigerung der lokalen Tumorkontrollrate führt die RT auch zu Verbesserungen der Überlebens- und der Mortalitätsraten. Die durch die RT bewirkten signifikanten Verbesserungen liegen in einem Bereich von $5-10 \%$, bezogen auf ein Zeitintervall von 20 Jahren, und sind in ihrer Höhe abhängig vom primären Tumorstadium. Eine postoperative RT der verbliebenen Brust nach brusterhaltender Operation verbessert die Prognose der Patientinnen und führt zu gleichen Langzeitergebnissen wie nach Mastektomie. Die Applikation einer Gesamtdosis von 50-50,4 Gy, appliziert in Einzeldosen von 1,8-2,0 Gy bei 5 Fraktionen pro Woche wird als Therapiestandard für eine Bestrahlung der verbliebenen Brust bzw. der Thoraxwand und der lokoregionalen Lymphabflusswege angesehen. Im Fokus aktueller Forschungen bei der radioonkologischen Primärtherapie von Patientinnen mit Mammakarzinom stehen Behandlungen mit weniger, allerdings höher dosierten Einzelfraktionen, mögliche Reduktionen des zu bestrahlenden Volumens nach BCS, genauere Auswahl von Patienten, die von einer RT des lokoregionalen Lymphabflusses profitieren, sowie der Einsatz unterschiedlicher Bestrahlungsformen (Brachytherapie, Bestrahlung mit Elektronen oder anderen Strahlenarten). Aktuelle interdisziplinäre Fragestellungen zum Einsatz der RT betreffen mögliche Interaktionen mit potentiell kardiotoxischen systemisch eingesetzten antineoplastischen Medikamenten, einen möglichen darin begründeten Einfluss auf die Therapiesequenz sowie die zeitliche Abfolge der Kombination von onkoplastischen operativen Maßnahmen und der RT. Auf diese Aspekte und zu erwartende Weiterentwicklungen bei der RT des Mammakarzinom wird in diesem Artikel besonders eingegangen.

\begin{tabular}{ll}
\hline KARGER & ( ) 2006 S. Karger GmbH, Freiburg \\
$\begin{array}{l}\text { Fax +49 7614520714 } \\
\begin{array}{l}\text { E-mail Information@Karger.de } \\
\text { www.karger.com }\end{array}\end{array}$ & $\begin{array}{l}\text { Accessible online at: } \\
\text { www.karger.com/brc }\end{array}$
\end{tabular}

PD Dr. med. Rainer Souchon

Allgemeines Krankenhaus Hagen gGmbH,

Gruenstr. 35, 58095 Hagen, Germany

Tel. +49 2331 201-2621, Fax -2637

E-mail souchon@akh-hagen.de 


\section{Introduction}

Independent of systemic antineoplastic therapy proven to be beneficial in systemic tumor control [1,2], locoregional transcutaneous radiation therapy (RT) improves local and locoregional control. In this way RT has become an integral part of a multimodal curative therapeutic concept in non-invasive and locally-limited invasive breast cancer [3-19]. Large prospective randomized clinical trials and recent metaanalyses have demonstrated that RT is a major independent prognostic factor with a positive influence on local and locoregional tumor control after mastectomy and after breast-conserving surgery (BCS) [3-9, 11, 12, 16-19]. Local recurrence rate is reduced by two thirds, the overall long-term reduction of local recurrence measures more than $20 \%[3,5,9,11,18]$. Rate of survival and quality of life are improved by this increased rate of tumor control. Depending upon the primary stage and related to an interval of 20 years, significant improvements achieved by RT measure from $5-10 \%$. After BCS, RT improves the prognosis, and long-term results are equal to those after mastectomy [3,8 $14,17]$. Due to rapid technical developments, the therapeutic index of curative RT will be further improved and individualized in the future. Current topics concerning the application of RT are possible interactions with potentially cardiotoxic systemically administered antineoplastic drugs, sequence of therapies as well as the combination with oncoplastic surgery. These aspects and further developments in RT of breast cancer will be treated in detail in this article.

Given the proven limited influence of systemic therapy on locoregional tumor control, it is noteworthy that current RT techniques add comparable beneficial effects to the prevention of locoregional tumor relapse. It has been recently shown that RT is not limited to these effects. Furthermore, RT has improved its undisputed clinical role in curative concepts in curative treatment of breast carcinoma as well as in early and advanced stages as it unequivocally has for several indications in palliative care. As for systemic treatment, the evidence of RT in treating breast cancer has been properly elucidated in numerous large clinical studies, prospective randomized trials and several metaanalyses, respectively, providing clinicians with a tool for balancing benefits and risks of RT in curative treatment settings. Improvements of local and locoregional tumor control, disease-free and overall survival as well as a positive impact on mortality rates by RT alone have been unanimously demonstrated to be independent of effects of systemic antineoplastic agents. Moreover, RT is able to sufficiently enhance the locoregional effects of antineoplastic systemic treatment. In this way, RT has been evaluated on highest levels of evidence to represent an independent prognostic factor and might clearly influence the outcome of patients with locoregional confined breast cancer [3-10]. These beneficial effects of RT have been demonstrated to be independent of differences in the extent of surgery for early breast cancer, i.e. mastectomy or BCS, and patient age [3,11-19]. To obtain the advantages of adjuvant RT the use of modern techniques in treatment planning and delivery is mandatory to minimize normal tissue exposure to radiation, particularly exposure of cardiac and pulmonary structures $[14,20]$.

Keeping this in mind, current clinical trials on breast cancer should place particular emphasis on interactions between systemic treatment with modern antineoplastic agents and RT. Likewise, more precise refinement of treatment sequencing is an issue in the multidisciplinary management of locally advanced and even in primarily operable breast cancer. This becomes obvious when considering that the 'optimal' timing of RT in primary systemic treatment is still unclear with regard to equieffectiveness of pre- or postoperative irradiation. Both scenarios have been investigated in relatively small trials only demonstrating the feasibility rather than equivalence or superiority of one particular approach for a single subgroup of patients. Therefore, this issue warrants further research and trials designed to determine which treatment sequence is most effective.

Other topics of interest are the integration of oncoplastic surgery and RT, or the use of accelerated partial breast irradiation in subsets of patients with BCS.

Of comparable clinical importance should be the role of RT in the context of an increasing number of oncoplastic surgeries or acceleration of treatment duration provided by partial breast RT approaches for breast cancer.

Any improvement of tumor control provided by locoregional irradiation in combination with modern antineoplastic drugs like taxanes, anthracyclines or trastuzumab has to be balanced against the risks of acute and late treatment-related toxicity. It should be noted that each treatment modality confers individual risks for either end-point. In particular, the risk of radiation-induced heart failure has been dramatically reduced over the last decades with the use of modern treatment planning techniques while cardiac risks by the increasing use of anthracyclines and trastuzumab are more frequently observed today. This article depicts some of these issues with particular focus on the use of modern RT.

\section{Clinical Importance of Local Tumor Control for Overall Survival}

Controlling clinically occult micrometastatic spread by systemic therapy, it is important to obtain local tumor control which is considered to be the key factor to maintain the chance of curing breast cancer [21]. The clinical importance of a local tumor is underlined by the fact, that locoregional recurrence and systemic tumor spread might not be necessarily independent factors in a subgroup of patients [17, 22-26]. Thus, in patients with locally limited disease at the time of breast cancer diagnosis, who consecutively develop an isolated locoregional recurrence, this relapse is a source of secondary systemic tumor spread in a part of the patients [22-29]. Al- 
though isolated locoregional relapse is an indicator of impending metastatic disease in the majority of patients, a significant minority of approximately $25 \%$ of the relevant patients is still free from metastases and can be cured, if the locoregional relapse is controlled by an appropriate treatment $[3$, 22-24, 26-29].

The recently published update of the metaanalysis of the Early Breast Cancer Trialists' Collaborative Group (EBCTCG) includes individual data of more than 42,000 patients treated in 78 randomized trials that tested the effects of RT and differences in the extent of surgery for early breast cancer on local recurrence and 15-year survival [3, 30]. Adjuvant RT after BCS and after mastectomy results in a 3 to 4-fold decrease of the locoregional recurrence rate in all subgroups independent of the absolute risk of locoregional recurrence [3-9, 11, 18, 23, 26, 31-41]. This gain in locoregional control translates into an absolute improvement of overall survival at 15 years of $5.3 \%$ after BCS $(p=0.005)$ and $4.4 \%$ in node-positive patients after mastectomy $(p=0.009)$. These findings should bring to an end the debate that has been going on for decades, whether or not a gain in locoregional tumor control improves survival. We have now unequivocal evidence that survival is improved. For every four locoregional recurrences avoided, one life is saved. The larger the risk of locoregional recurrence the larger the gain in overall survival. As a consequence of the underlying mechanism, the avoidance of secondary metastases originating from the locoregional recurrence, the survival curves do not separate before 5 years after RT, and a significant benefit is not observed before 10 years after therapy. It should be noted that the improvement of survival resulting from adjuvant RT is not influenced by duration of follow-up [3, 11, 32, 42-44].

A number of important questions arise regarding the consequences of these findings for clinical practice. If the avoidance of locoregional recurrences saves lives, should we treat our patients with more extensive surgery or more RT? Is BCS safe? To answer these questions, it is important to understand that a gain in overall survival is unlikely to be detected in clinical trials and metaanalyses, if the absolute gain in locoregional control of a specific treatment is below $5-10 \%$.

\section{Breast Conserving Surgery (BCS)}

In the metaanalysis of trials that compare mastectomy $(+/-$ adjuvant systemic treatment) with BCS followed by RT (+/- adjuvant systemic treatment) the absolute rates of isolated locoregional recurrence at 5 years were 5.3 and $8.6 \%$ for nodenegative disease $(p<0.05)$, and 7.9 and $4.9 \%$ for node-positive disease (n.s.), respectively. Accordingly, the risk of isolated locoregional recurrences after BCS + RT is 3.3\% higher in node-negativ (N0) and 3.1\% lower in node-positive $(\mathrm{N}+)$ patients compared to mastectomy. These differences in locoregional control are too small to result in a difference in overall survival as shown in the metaanalysis $[3,9]$. The risk of locoregional recurrences has been shown to be considerably higher in premenopausal patients (relative risk, $\mathrm{RR}=1.60$ for patients aged $35-50$ years and 2.34 for patients $<35$ regardless whether treated by mastectomy or by BCS + RT [45]. The absolute 10-year risk of isolated locoregional recurrences in the subgroup of young patients ( $<40$ years) even in studies that use additional systemic treatment ranges between $10-15 \%$ after mastectomy $[44,46]$ and 20-30\% after BCS + RT [46, 47]. This difference in locoregional recurrence rate of, on average, $10-15 \%$ would theoretically be large enough to postulate a decrease of $2.5-3.8 \%$ in overall survival for BCS + RT compared with mastectomy. The subgroup of young patients in the randomized trials is too small to exclude a disadvantage of that magnitude. However, by increasing the dose restricted to the tumor bed to $66 \mathrm{~Gy}$ after whole breast RT to $50 \mathrm{~Gy}$, the EORTC [47], in one of the largest RT trials ever conducted ( $\mathrm{n}=5,318)$, was able to demonstrate that this boost reduces the hazard of locoregional relapse after BCS by $41 \%$. In patients $<40$ years the recurrence rate in the ipsilateral breast was decreased from 29 to $10 \%$ at 8 years, i.e. not in excess of the rates observed after mastectomy. One could further argue that mastectomy followed by RT is an even safer option for young patients. However, no survival benefit could be demonstrated in the EBCTCG metaanalysis for the addition of postmastectomy radiotherapy (PMRT) in subgroups with $<10 \%$ risk of isolated locoregional recurrence. The modest reduction of breast cancer specific mortality in this subgroup is counterbalanced by a modest increase of the non-breast cancer specific mortality as will be discussed later. The bottom line is that $\mathrm{BCS}+\mathrm{RT}$ can be considered a safe treatment for all age groups, provided that contraindication for BCS, like large or inflammatory tumors or multi-centric growth, are not ignored, especially in young patients.

\section{Postmastectomy Radiotherapy (PMRT)}

Although the EBCTCG metaanalysis published in 2000 had not shown a statistically significant survival benefit [4], the impressive survival benefits observed in the Danish trials $[48,49]$ and the Canadian trial [50] encouraged all Cancer Societies to recommend PMRT for high-risk patients (T3, T4, and $>3$ positive lymph nodes) [51-54]. The 2005 update of the EBCTCG metaanalysis further substantiates this appreciation for nodepositive patients based on a 15-year follow up of 8,505 individual patient's data. RT decreased isolated locoregional recurrence rates from 29.2 to $7.8 \%$ at 15 years corresponding to a $5.4 \%$ survival advantage $(\mathrm{p}=0.0002)$. According to the additionally published web-material, information on the number of pathologically involved axillary lymph nodes were available of only 3,758 patients at the time of publication. In the subgroup analysis based on this number of patients, a significant gain in overall survival was observed for patients with $>3$ lymph nodes involved, but not for patients with 1-3 positive nodes. However, in the meantime the EBCTCG analyzed the pathology reports of 7,574 patients in September 2006 and presented the unpublished data in October 2006 at the 25th 
Annual Meeting of the European Society for Therapeutic Radiology and Oncology (ESTRO25) in Leipzig and in November 2006 at the 48th Annual Meeting of the American Society for Therapeutic Radiology and Oncology (ASTRO). In patients with $1-3$ positive nodes $(\mathrm{n}=3,344)$, PMRT decreases isolated locoregional recurrence at 15 years from 24.3 to $5.3 \%$ and results in a gain of overall survival of $5.3 \%(p=0.05)$. In patients with $>3$ positive nodes $(n=2,876)$, isolated locoregional relapse drops from 40.6 to $12.9 \%$ corresponding to a survival gain of $6.2 \%(\mathrm{p}=0.003)$. Patients with no involved nodes $(n=1,354)$ have a $3.9 \%$ worse survival $(p=0.0005)$ in the case of PMRT [30]. This is important new information, indicating one should offer PMRT to all node-positive patients.

\section{Excess Risk of Non-Breast Cancer Deaths after RT and the Impact of Modern Radiation Techniques on these Effects}

This review focuses on the effects of RT on long-term mortality not caused by primary breast cancer and will leave out discussions on quality of life and cosmesis. What is the price to pay for the benefits of RT?

Again, the latest and most relevant data come from the EBCTCG [3]. Based on the data of more than 20,000 women with at least 15 years follow up, three relevant risks can be identified that are associated with the use of RT: The relative risks to develop contralateral breast cancer (1), to die from heart disease (2), or to die from lung cancer (3) are increased by $1.18(\mathrm{p}=0.002), 1.27(\mathrm{p}=0.0001)$, and $1.78(\mathrm{p}=0.0004)$, respectively. The relative risk for non-breast cancer deaths is enhanced by factor 1.12 ( $\mathrm{p}=0.001)$. The effects were not age dependent. However, the absolute effects are quite small. At 15 years, an increase of the rate of contralateral breast cancer from 7.5 to $9.3 \%$, and of the rate of all non-breast cancer deaths from 14.6 to $15.9 \%$ was observed. Whereas the excess risk to develop contralateral breast cancer was particularly seen 5-15 years after RT, the excess risk for non-breast cancer deaths is not detectable before 5-10 years after RT, but seems to increase continuously afterwards, especially after more than 15 years of follow up. It has to be kept in mind, however, that the majority of patients with more than 15 years of follow up received RT between 1970 and 1975, that is, with a somewhat outdated radiation technique.

The question arises whether the same excess risk of deaths associated with RT is observed, if modern radiation techniques are employed. Megavoltage energy, 3D treatment planning, and immobilization devices ensuring reproducible positioning have been gradually introduced into the daily practice of radiation oncologists, starting approximately 25 years ago. Cardiovascular diseases, especially coronary heart disease and myocardial infarction were observed considerably more frequently after RT for left-sided breast cancer than for rightsided breast cancer in studies that treated the patients before
1980. In a recently published metaanalysis [55] no difference in the incidence of ischemic heart disease was seen 15 years after RT between left and right-sided cancers, if the RT was administered after 1984. In the combined analysis of the Danish post-mastectomy trials [56] no excess risk of heart disease was found in irradiated patients 12 years after treatment. These observations suggest that an excess risk of cardiac deaths is not observed, if modern radiation techniques are used.

If the excess risk to develop secondary cancer, in particular contralateral breast and lung cancer, can also be diminished by the use of modern photon RT technology is at least questionable. The amount of healthy tissue exposed to high radiation doses is smaller, if modern equipment is used, but the volume exposed to small radiation doses is approximately the same or maybe even higher, if intensity-modulated radiotherapy (IMRT) is used improvidently. Since no clear dose response curve exists for the induction of secondary cancers above approximately 10 Gy [57], lower doses to larger volumes are potentially hazardous and should not be accepted for marginal improvement of dose distribution in the highdose volume especially in younger patients.

Present standard technology of RT is certainly associated with a lower excess risk of non-breast cancer deaths than was reported in the EBCTCG metaanalysis. However, some hazard remains. The impact of future developments on this issue is discussed later

\section{Sequence of Radiation and Systemic Therapy}

\section{Adjuvant Chemotherapy}

The vast majority of breast cancer patients receives adjuvant systemic treatment as well as RT. Delayed administration of RT, especially later than 8 weeks after surgery, approximately doubles the relative risk to develop a locoregional recurrence according to the results of a metaanalysis [58]. However, most studies included were retrospective and almost half of the studies were considered to be of low quality. One high-quality randomized trial compared chemotherapy first (12 weeks CAMF) followed by RT with RT first followed by chemotherapy (12 weeks CAMF). The early result, published in 1996 [59], indicated that chemotherapy first might be the better option, because survival without evidence of distant metastasis was $11 \%$ better in this sequence $(\mathrm{p}=0.05)$, although this had not translated into a significant gain in overall survival at the time of publication. Most experts were convinced that a significant survival benefit would only be a matter of longer follow up. However, in the update of this study [60] neither overall survival nor metastasis-free survival were statistically different, even though there was still a slight trend to a lower rate of distant disease. Locoregional control was lower in the chemotherapy-first arm of the study, especially if the resection margin was close $(<2 \mathrm{~mm})$. The available data do not justify 
an evidence-based recommendation for the sequence of chemotherapy and RT. Adjuvant chemotherapy schedules containing taxanes cause a further delay of RT, if the taxanes are given subsequently to the anthracyline containing regimens. Concerns of radiation oncologist that this delay would cause more locoregional recurrences seem not to apply. The CALGB randomly assigned patients to receive adjuvant $\mathrm{AC}$ versus AC followed by paclitaxel chemotherapy [61]. RT was required if BCS was performed but was elective after mastectomy. In patients who received AC, RT started on average at day 60 after surgery, whereas in the paclitaxel arm of the study RT began on average at day 126 after surgery. Locoregional control at 5 years was identical in both arms of the study after mastectomy and even significantly better in the paclitaxel arm of the study. These results indicate that in clinical practice adjuvant chemotherapy before RT is safe. In the case of a very close resection margin, one should however discuss RT first, especially in patients with low risk of distant disease. Another option is concomitant chemoradiotherapy. However, acute and late toxicity are enhanced especially if anthracyclines are part of the treatment [62]. Outside of clinical trials, this option should only be considered for patients with a very high risk for distant and local relapse.

\section{Adjuvant Endocrine Treatment}

Most available information refers to the use of adjuvant tamoxifen. Although some experimental data suggest that tamoxifen might decrease radiation sensitivity of breast cancer cells in vitro, clinical data do not substantiate this observation $[63,64]$. Moderately increased risks for late pulmonary damage and subcutaneous fibrosis have been reported at least for subsets of patients $[65,66]$. In the case of irradiation of large lung volumes it might be wise to avoid concomitant tamoxifen, but generally tamoxifen is not contraindicated during RT. However, clinical data do not suggest that locoregional control is inferior in the case of subsequent treatment.

Aromatase inhibitors have been introduced in the adjuvant treatment of breast cancer and are widely used. In the large trials [67-69] approximately $60 \%$ of patients received RT. No information is available on how many women received the aromatase inhibitor simultaneously with RT and no subgroup analyses of specific side effects in irradiated patients have been published. Nevertheless, the toxicity profiles of the aromatase inhibitors in these studies do not point to the enhancement of typical radiation-induced acute or late toxicity. In addition, from the mechanism of action of these drugs such an interaction with radiation appears unlikely. Treatment with aromatase inhibitors concomitantly or subsequent to RT seems to be safe.

\section{Trastuzumab}

Adjuvant treatment with trastuzumab has become standard of care for patients with tumors that overexpress HER2/neu [70-72]. In the American trial [72] trastuzumab was given dur- ing RT to a considerable number of patients. In a presentation given at the ECCO meeting 2005 in Paris no enhanced cardiac or other toxicities have been reported for the combination of RT and trastuzumab. However, follow up was very limited at the time of analysis and no published material is available. Furthermore, one has to keep in mind that parasternal irradiation was not allowed in this trial. In a small study presented at the ASCO 2006 [73], trastuzumab in combination with concurrent RT significantly enhanced cardiac, esophageal and skin toxicity. 41 out of 95 patients in this study received parasternal radiation, which might explain the increased cardiac toxicity. Outside of clinical trials concomitant RT and trastuzumab should not be considered standard of care, especially if a significant part of the heart is within the radiation portals.

\section{Radiation Regimens and Target Volumes}

Whole breast RT with a total dose of 50-50.4 Gy in 1.8-2.0 Gy fractions 5 times per week is considered standard therapy in most countries. In the United Kingdom shorter fractionation schedules have been tested for whole breast RT. Between 1986 and 1998, 1,410 women with invasive breast cancer were randomly assigned (tumor stage $1-3, \leq 1$ positive node and no metastasis) who had had local tumor excision of early-stage breast cancer to receive 50 Gy RT given in 25 fractions, 39 Gy given in 13 fractions, or 42.9 Gy given in 13 fractions, all given over 5 weeks $[74,75]$. The local recurrence rate after 10 years was $12.1 \%$ (95\% CI $8.8-15.5)$ in the 50 Gy group, $14.8 \%$ (11.2-18.3) in the 39 Gy group, and 9.6\% (6.7-12.6) in the 42.9 Gy group (difference between 39 Gy and 42.9 Gy groups, $\mathrm{p}=0.027$ ). The cosmetic results were very similar in the $50 \mathrm{~Gy}$ and 39 Gy group, but significantly worse in the 42.9 Gy group. Electron boost irradiation (14 Gy in 7 fractions) deteriorated the cosmetic results in all arms of the study. The findings of this study suggest that RT schedules could be simplified by the delivery of fewer, larger fractions without compromising effectiveness or safety. However, most radiation oncologists think that confirmation of this result in an independent trial is needed, before such schedules are broadly introduced into daily practice.

According to the results of the EORTC boost trial, patients $<50$ years benefit from a boost of $16 \mathrm{~Gy}$ ( 2 Gy single dose) to the tumor bed. The absolute gain in local control at 7 years accounts for almost $20 \%$ of patients $<40$ years and $5 \%$ of patients aged 40-50 years [47]. The reduction of the relative risk is similar in all age groups and the 2006 unpublished update of the studies shows a statistically significant reduction of local relapses also for the group of patients aged $>50$ [Bartelink et al., at the ESTRO 25 Meeting 2006, abstract]. Irrespective of age, a boost should be also given in the case of positive or close tumor-free surgical margins $(<2 \mathrm{~mm})$ [Poortmanns et al., at the ESTRO 25 Meeting 2006, abstract 54] or in hormone re- 
ceptor-negative high-grade tumors, even the latter indication is based on retrospective data only. The optimal boost dose is unknown, but all studies testing the boost and having a positive result used 10-16 Gy. Whether a higher boost to 26 Gy is beneficial for young patients is being tested in an ongoing Dutch trial.

The target volume for RT after BCS has empirically been considered to be the whole breast. However, a number of clinical studies have shown that in low-risk patients (tumors $<2 \mathrm{~cm}, \mathrm{G} 1 / 2$, pN0, and age $>50$ years) in-breast recurrences $>1-2 \mathrm{~cm}$ distant from the primary tumor occur in less than $5-10 \%$ of cases. These patients might successfully be treated by partial breast irradiation. Different intraoperative and postoperative radiation techniques (brachytherapy, electron beams, IMRT and others) have been used and early results look promising [for review see: 76]. Outside clinical trials, one should not recommend partial breast irradiation yet, although it appears likely that there will be indications for these procedures in the future.

Another unresolved issue are indications for elective irradiation of axillary, supraclavicular, and parasternal lymph nodes. One the one hand, one has to keep in mind that in most studies that were included into the EBCTCG metaanalysis [3], at least in the post-mastectomy setting, all nodal areas were irradiated. On the other hand, it is likely that the excess risk of non-breast cancer deaths observed in these studies somehow is linked with elective nodal irradiation, especially from the parasternal radiation fields. Subgroup analyses indicate that elective axillary RT does not improve the results unless residual tumor is suspected (R1/R2) and that elective irradiation of the nodal areas leaving out the chest wall is of no significant benefit, but do not resolve the question, in which cases RT of the one or the other nodal area should be done. We have to wait for the disclosure of a large EORTC trial $(n=4,004)$ that randomly allocated moderate and high-risk patients to elective node RT (supraclavicular and parasternal) in addition to chest wall or whole breast RT or no elective nodal RT. So far, routine use of parasternal irradiation is not recommended in any guideline. Since the risk of supraclavicular lymph node involvement is $>15 \%$ in cases with $>3$ involved axillary nodes [51-54], elective irradiation is recommended in most guidelines. The dose at the plexus brachialis should not exceed 50 Gy in 1.8-2.0 Gy single doses, because otherwise a high incidence of brachial plexopathy could occur in the long term [77].

\section{Omission of RT in Patients with Presumed Low Risk of Local Relapse}

For improvements of survival due to RT, postoperative irradiation has to have the capability to eradicate residual locoregional tumor deposits which might cause local recurrence as well as systemic tumor spread, if they postoperatively remain untreated and systemic antineoplastic agents fail to sterilize these residuals $[4,78,79]$. Therefore, definition of individual risk factors using specific criteria for predicting enough patients who might have microscopic locoregional tumor is warranted. There might be a consensus to define a low, intermediate or high risk of disease recurrence encompassing probabilities of $<10 \%, 10-20 \%$, and $>20 \%$, respectively [21].

Patients with non-invasive ductal carcinoma in situ (DCIS) as well as invasive breast cancers are considered to have presumably favorable prognostic factors when presenting with a small tumor size $(<1 \mathrm{~cm})$, endocrine responsiveness with positivity of estrogen receptors, no ipsilateral lymph node involvement, or low grading.

Patients presumed to have a low risk of tumor relapse, were treated in several clinical trials with the intention to spare patients the potential risks as well as the inconvenience of adjuvant RT. These approaches performed in patients with either invasive or non-invasive breast cancer, consistently resulted in a substantial increase in local relapse [80-87]. All these trials failed to identify cohorts of patients that would not benefit from adjuvant treatment. Concluding these data, even in this subset of patients ipsilateral breast cancer recurrence after BCS occurs frequently enough to justify postoperative irradiation, regardless of adjuvant systemic endocrine treatment with tamoxifen [87-89].

As far as DCIS is concerned, a low risk of relapse was assumed for the combination of tumor size $<2 \mathrm{~cm}$, low grade nuclear grading, width of resection margins $>10 \mathrm{~mm}$ and age $>50$ years [90-92]. For patients who fulfill these criteria recommendations in national guidelines regarding postoperative irradiation after BCS included avoidance of breast irradiation by an individual-based decision making [50, 93]. In contrast to these recommendations, Wong et al. [87] recently demonstrated, that despite margins of $\geq 1 \mathrm{~cm}$, local recurrence rate was substantial when patients with small, grade 1 or 2 DCIS were treated with wide excision alone. The rate of ipsilateral local recurrence as first site of treatment failure was $2.4 \%$ per patient-year, corresponding to a 5-year rate of $12 \%$. Another trial addressing this issue, the RTOG 9804, is still recruiting and mature data are pending [94]. However, recently published data of controlled clinical trials [87, 88, 95] prompted the German Society of Radiation Oncology to update recommendation for RT in DCIS [96].

\section{Presurgical Radiotherapy in Patients Receiving Primary Systemic Therapy}

The rationale for adding RT to primary (synonymous: neoadjuvant) systemic treatment (NST) before surgery is the expectation of combined synergistic lethal effects on tumor cells. Thus, applying radiation prior to surgery may improve tumor shrinkage and increase the rate of pathologically complete responses (pCR). Chemotherapy fails to induce a pCR in up to 
three-fourth of patients [97, 98]. Even in patients reaching clinically CR after NST, up to one third will have pathological evidence of residual disease in the breast and up to one half of them in axillary nodes.

The rates of pCR that imply a long-term relapse-free state might also be influenced by additional RT. Thus, additional RT prior to surgery might be of advantage in T3 or T4 tumors and even in otherwise operable stage I and II, to aim at greater rates of breast preservation [99-104]. However, in patients achieving response to NST, it is still unknown whether preoperative RT following NST yields similar results in terms of progression-free survival (PFS), overall survival and locoregional disease control as compared with adjuvant RT and surgery first after NST $[25,105]$.

Nevertheless, the concept of preoperative RT in addition to NST as a strategy has not yet been proven in controlled clinical trials which recruited cohorts large enough to reach sufficiently high levels of evidence and so demonstrating unanimous superiority in terms of higher rates of pCR or breast preservation.

Thus, preoperative irradiation is not yet established as a mode of treatment in conjunction with NST $[99,106]$ and does not replace adequate surgery [105, 107]. Furthermore, following questions in presurgical RT are still to be answered: Which sites have to be irradiated? Which volume has to be treated? Which dose has to be delivered? And most importantly, do complete responders after NST and RT fare as well or better than responders after NST?

The next generation of controlled clinical trials has to address the optimal interactions between NST and RT to determine their relative roles in the management of patients with operable breast cancer in order to define subgroups of patients who might benefit in particular from additional RT [108].

Recommendations regarding postoperative RT following NST are limited to patients suffering from inflammatory or locally advanced breast cancer who subsequently achieved a pCR. These patients still have a high rate of local-regional recurrences and profit from adjuvant post-mastectomy irradiation [25]. In patients with $\mathrm{T} 1$ or $\mathrm{T} 2$ disease and 1-3 lymph nodes involved, the 5-year risk of local regional recurrence might be low and does not justify the application of PMRT [101]. In the case of no or poor response to NST, alternative strategies should include RT.

Summarizing limited data for preoperative RT in addition to NST, RT might improve rates of pCR and breast preservation. However, this has not yet been proven in cohorts large enough to reach sufficiently high levels of evidence.

\section{Radiation Therapy and Oncoplastic Surgery}

Even though BCS is the standard procedure in the majority of patients, there remains a proportion of $30-40 \%$ of breast cancer patients in whom mastectomy is performed due to cancer characteristics that prohibit breast conservation or due to individual patient preference. Mastectomy is conflicted with a radical change in the patient's body image and may therefore confer a substantial psychological burden. To overcome the severe changes in physical appearance and inherent psychosocial morbidity, breast reconstruction has gained increasing acceptance in recent years. A variety of reconstruction techniques is available today offering women the chance to regain a natural-like breast appearance. Particular consideration has to be paid to patients opting for oncoplastic surgery if adjuvant RT is indicated. A large number of reports has emphasized that breast reconstruction in conjunction with irradiation is conflicted with a high incidence of early and late complications as compared to women with breast reconstruction alone [109-112]. Early complications like impaired wound-healing, blood vessel thrombosis, skin flap necrosis, partial or total flap loss, and late sequelae, like severe fibrosis, soft tissue contracture, displacement of breast implants, fat necrosis, chronic pain, and unsatisfactory cosmetic outcome are the most frequent hazards of combining breast reconstruction and RT. As a rough estimate it can be assumed that the complication rate in patients undergoing RT and reconstructive breast surgery is twice as high as in those patients that do not require irradiation $[112,113]$. However, the data reported are inhomogeneous and the variables that have an impact on the ultimate outcome need to be analyzed carefully.

From a therapeutic point of view the most important factors that are subject of deliberate decision in patients requiring adjuvant RT and desiring breast reconstruction are the timing (immediate vs. delayed), the extent and type of oncoplastic surgery, the use of autologous tissues vs. implants, and the sequence of breast reconstructive surgery and irradiation [111, 114, 115].

Breast reconstruction with the use of expander and implants $(\mathrm{E} / \mathrm{I})$ is associated with a considerable risk of complications $[112,113,116,117]$. Krueger et al. [112] reported a rate of reconstruction failures in patients with E/I-reconstruction with additional RT of $37 \%$ as compared to $8 \%$ for patients without irradiation. The sequence of reconstruction and RT was of no significant influence in this retrospective study which may have been due to the small sample size. Similar complication rates were reported by Tallet et al. [113] and Contant et al. [116] with capsular contraction being the most frequent reason for secondary surgery after reconstruction. Use of adjuvant chemotherapy was associated with an increased failure rate in this study. Chawla et al. [109] compared autologous reconstruction with transverse rectus abdominis myocutaneous (TRAM) flap with E/I reconstructions. The actuarial 2-year complication rate was $53 \%$ for patients receiving E/I as compared to $12 \%$ for TRAM reconstruction. This corresponded to a significantly better cosmetic outcome after TRAM reconstruction. No other treatment-related factors had an impact on complications. 
Tran et al. [115] demonstrated that the sequence of postmastectomy breast reconstruction and RT is an important factor which has an impact mainly on late complications of treatment. In patients with TRAM reconstruction followed by RT they observed rates of fat necrosis, flap volume loss, or flap contracture of $43.8,87.5$, and $75 \%$, respectively. The corresponding figures in patients with RT before TRAM reconstruction were $8.6,0$, and $0 \%$, respectively.

In summary, the data point to the following strategy: Immediate breast reconstruction should be avoided in patients known to require PMRT and should be delayed until RT is completed $[111,114]$. Heterologous reconstruction in these patients is conflicted with numerous late toxicities and should, if possible, be avoided. Oncoplastic surgery after RT with heterologous material is hampered by radiation-induced fibrosis of the chest wall that impairs expansion of skin and musculature. Furthermore, capsular fibrosis of the implant will aggravate local fibrosis. As a result, pain, capsular contracture as well as displacement of the implant and unpleasing cosmetic outcomes may occur. The underlying mechanisms that have an impact on the ultimate outcome of breast reconstruction in patients submitted to RT are still to be clarified. However, induction of fibrosis, either by RT or by implants, plays a major role.

Instead, autologous reconstruction is the preferred type of oncoplastic surgery in these patients.

Patients with BCS who undergo breast augmentation with implants followed by RT were studied by Victor et al. [118]. They reported an excellent cosmetic outcome in these patients as compared to those with breast reconstruction after mastectomy followed by RT.

Undoubtedly, autologous reconstruction may be technically more demanding. Nevertheless, breast reconstruction with e.g. TRAM or latissimus dorsi flaps after chest wall irradiation has the inherent advantage that skin and soft tissue moved into the former site of radiation afterwards will not be subjected to progressive radiation-induced fibrosis. Therefore, a soft, natural-like reconstructed breast is more likely to result.

However, assumptions of clinically relevant differences regarding tolerability, complication rates and cosmetic result, respectively, in patients who had immediate breast reconstruction using TRAM or latissimus dorsi flaps procedures and who have to undergo RT afterwards, are not supported by published trials.

With regard to technical aspects of RT, a recent report demonstrated a potential negative impact of immediate breast reconstruction on RT planning. [119]. In particular, lung minimization, avoidance of the heart and coverage of internal mammary chain was impaired in patients with breast reconstruction as compared to patients planned after mastectomy alone. These aspects might reduce the therapeutic index of RT and should be carefully considered when counselling patients who require RT and who opt for breast reconstruction at the same time.

\section{Perspectives in Radiation Therapy for Breast Cancer}

Geometrical precise as well as safe and effective delivery of an oncologically needed high total radiation dose to a clinical target volume and an optimal dose distribution, while sparing adjacent critical normal tissues still remains the goal of radiation oncology not only in breast cancer. In recent years several attempts have been successfully made to improve delivery of $\mathrm{RT}$ in order to enhance local and locoregional tumor control and to lower risks of radiation-induced toxicity and late sequelae. Further advancements in this field include new technologies for delivery such as sophisticated forms of 3D conformal RT, e.g. intensity modulated radiation therapy (IMRT) by use of non-uniform radiation beam intensities incident on the patient to shape the dose distribution in the clinical target volume and the adjacent normal tissues. IMRT is superior to conventional RT to cover the oncologically desired high radiation dose limited to the clinical target volume more precisely and to encompass this region with an optimal dose distribution. The volume exposed to a low radiation dose is somewhat larger with IMRT, resulting, at least in theory, in a slighty increased risk of secondary cancers. However, in the case of provident arrangements of radiation fields this excess risk can be minimized [120]. It is still unanswered if these operational aspects of target volume delineation and radiation treatment planning will be changed by IMRT technology and influence treatment outcome or not. Further technical advances might be expected even by use of image-guided radiotherapy (IGRT). IGRT will help optimize distribution of the radiation dose during radiation treatment to be appropriate and provides a safe delivery [121]. Proton beam RT using the scanning beam technique can be used to further improve the conformity of the treatment and, even more important, to reduce unnecessary low dose irradiation outside the target volume. The latter would at least theoretically decrease the excess risk of radiation-induced secondary cancers (especially lung and contralateral breast cancers).

While IMRT and IGRT are likely to be integrated into the clinical routine of RT over the next decades, the high costs of proton beams may impede their broad use in daily routine. Furthermore, a dawn on high-precision radiation oncology is ongoing: the biologically optimized dose distribution of RT [122]. Progress is made in molecular imaging and cancer biology as well as in functional imaging which might have additional impact on further optimization of radiation treatment based on individual biological and validated prognostically relevant tumor parameters. Molecular imaging-based biological assessment of the individual risk of local or regional and systemic recurrence of breast cancer, respectively, should become possible and could influence indication and extent of RT. These new developments should take advantage of improvements in defining risk groups of patients with individually tailored treatment strategies including the choice and technique of adjuvant RT. 


\section{References}

1 Clarke M: Meta-analyses of adjuvant therapies for women with early breast cancer: the Early Breast Cancer Trialists' Collaborative Group overview. Ann Oncol 2006;suppl 10:x59-x62.

$>2$ Early Breast Cancer Trialists' Collaborative Group (EBCTCG): Effects of chemotherapy and hormonal therapy for early breast cancer on recurrence and 15-year survival: an overview of the randomised trials. Lancet 2005;365(9472):1687-717.

3 Clarke M, Collins R, Darby S, Davies C, Elphinstone P, Evans E, Godwin J, Gray R, Hicks C, James S, MacKinnon E, McGale P, McHugh T, Peto R, Taylor C, Wang Y; Early Breast Cancer Trialists' Collaborative Group (EBCTCG): Effects of radiotherapy and of differences in the extent of surgery for early breast cancer on local recurrence and 15year survival: an overview of the randomised trials. Lancet 2005;366:2087-106.

4 Early Breast Cancer Trialists' Collaborative Group: Favourable and unfavourable effects on long-term survival of radiotherapy for early breast cancer: an overview of the randomised trials. Lancet 2000;355 1757-70.

$\checkmark 5$ Gebski V, Lagleva M, Keech A, et al.: Survival effects of postmastectomy adjuvant radiation therapy using biologically equivalent doses: a clinical perspective. J Natl Cancer Inst 2006;98:26-38.

6 Nielsen HM, Overgaard M, Grau C, Jensen AR, Overgaard J: Study of failure pattern among highrisk breast cancer patients with or without postmastectomy radiotherapy in addition to adjuvant systemic therapy: long-term results from the Danish Breast Cancer Cooperative Group DBCG 82 b and c randomized studies. J Clin Oncol 2006;24: 2268-75.

$\checkmark 7$ Nielsen HM, Overgaard M, Grau C, Jensen AR, Overgaard J: Loco-regional recurrence after mastectomy in high-risk breast cancer-risk and prognosis. An analysis of patients from the DBCG $82 \mathrm{~b}$ and c randomization trials. Radiother Oncol 2006; 79:147-55.

8 Vinh-Hung V, Verschraegen C: Breast-conserving surgery with or without radiotherapy: pooledanalysis for risks of ipsilateral breast tumor recurrence and mortality. J Natl Cancer Inst 2004;96: $115-21$.

9 Wapnir IL, Anderson SJ, Mamounas EP, Geyer CE Jr, Jeong JH, Tan-Chiu E, Fisher B, Wolmark N: Prognosis after ipsilateral breast tumor recurrence and locoregional recurrences in five National Surgical Adjuvant Breast and Bowel Project Node-Positive Adjuvant Breast Cancer Trials. J Clin Oncol 2006;24:2028-37.

10 Whelan T, Levine M: More evidence that locoregional radiation therapy improves survival: what should we do? J Natl Cancer Inst 2005;97:82-4.

11 Fisher B, Anderson S, Bryant J, et al.: Twenty-year follow-up of a randomized trial comparing total mastectomy, lumpectomy, and lumpectomy plus irradiation for the treatment of invasive breast cancer. N Engl J Med 2002;347:1233-41.

12 Lee JC, Truong PT, Kader HA, Speers CH, Olivotto IA: Postmastectomy radiotherapy reduces locoregional recurrence in elderly women with highrisk breast cancer. Clin Oncol (R Coll Radiol) 2005;17:623-9.

13 Olivotto IA, Truong PT, Chua B: Postmastectomy radiation therapy: who needs it? J Clin Oncol 2004;22:4237-9.

14 Palazzi M, Tomatis S, Valli MC, Guzzetti R, Tonoli S, Bertoni F, Magrini SM, Meregalli S, Asnaghi D, Arienti V, Pradella R, Cafaro I: Impact of radiotherapy technique on the outcome of early breast cancer treated with conservative surgery: A multicenter observational study on 1,176 patients. Int J Radiat Oncol Biol Phys 2006;65:1361-7.
15 Truong PT, Olivotto IA, Kadar HA, Panades M, Speers $\mathrm{CH}$, Barthelet E: Selecting breast cancer patients with T1-T2 tumors and one to three positive axillary nodes at high postmastectomy locoregional recurrence risk for adjuvant radiotherapy. Int J Radiat Oncol Biol Phys 2005;61:1337-47.

16 Truong PT, Lee J, Kader HA, Speers CH, Olivotto IA: Locoregional recurrence risks in elderly breast cancer patients treated with mastectomy without adjuvant radiotherapy. Eur J Cancer 2005;41: 1267-77.

17 Vrieling C, Collette L, Fourquet A, Hoogenraad WJ, Horiot JC, Jager JJ, Bing Oei S, Peterse HL, Pierart M, Poortmans PM, Struikmans H, Van den Bogaert W, Bartelink H; EORTC Radiotherapy, Breast Cancer Groups: Can patient-, treatmentand pathology-related characteristics explain the high local recurrence rate following breast-conserving therapy in young patients? Eur J Cancer 2003; 39:932-44.

18 Whelan TJ, Julian J, Wright J, et al.: Does locoregional radiation therapy improve survival in breast cancer? A meta-analysis. J Clin Oncol 2000;18: 1220-9.

19 Zhou P, Recht A: Young age and outcome for women with early-stage invasive breast carcinoma. Cancer 2004;101:1264-74.

20 Prosnitz LR, Marks LB: Postmastectomy radiotherapy: quality counts! J Natl Cancer Inst 2006;98:3-4.

21 Pierce LJ: The use of radiotherapy after mastectomy: A review of the literature. J Clin Oncol 2005; 23:1706-17.

22 Dunst J, Steil B, Furch S, et al.: Prognostic significance of local recurrence in breast cancer after postmastectomy radiotherapy. Strahlenther Onkol 2001;17:504-10.

23 Early Breast Cancer Trialists' Collaborative Group: Effects of radiotherapy and surgery in early breast cancer: an overview of the randomised trials. $\mathrm{N}$ Engl J Med 1995;333:1444-55.

24 Hölzel D, Engel J, Schmidt M, et al.: Sekundäre Metastasierung aus lokoregionalen Rezidiven eines Mammakarzinoms. Strahlenther Onkol 2001;177: 10-24.

25 Huang EH, Tucker SL, Strom EA, et al.: Postmastectomy radiation improves local-regional control and survival for selected patients with locally advanced breast cancer treated with neoadjuvant chemotherapy and mastectomy. J Clin Oncol 2004; 22:4691-9.

26 Veronesi U, Marubini E, del Vecchio M, et al.: Local recurrences and distant metastases after conservative breast cancer treatments: Partly independant events. J Natl Cancer Inst 1995;87:19-27.

27 van Tienhoven G, Voogd AC, Peterse JL, et al.: Prognosis after treatment for loco-regional recurrence after mastectomy or breast conserving therapy in two randomised trials (EORTC 10801 and DBCG-82TM). EORTC Breast Cancer Cooperative Group and the Danish Breast Cancer Cooperative Group. Eur J Cancer 1999;35:32-8.

28 Schmoor C, Sauerbrei W, Bastert G, et al.: Role of isolated locoregional recurrence of breast cancer: results of four prospective studies. J Clin Oncol 2000;18:1696-708.

29 Wallgren A, Bonetti M, Gelber RD, et al.: International Breast Cancer Study Group Trials I through VII. Risk factors for locoregional recurrence among breast cancer patients: results from International Breast Cancer Study Group Trials I through VII. J Clin Oncol 2003;21:1205-13.
30 McGale P, Darby S, Taylor C, Peto R: The 2006 Worldwide overview of the effects of local treatments for early breast cancer on long-term outcome. Int J Radiat Oncol Biol Phys 2006;66(suppl): S2-S3 (plenary 4).

31 Van de Steene J, Soete G, Storme G: Adjuvant radiotherapy for breast cancer significantly improves overall survival: the missing link. Radiother Oncol 2000;55:263-72.

32 Van de Steene J, Vinh-Hung V, Cutuli B, Storme G: Adjuvant radiotherapy for breast cancer: effects of longer follow-up. Radiother Oncol 2004;72:35-43.

33 Malmström P, Holmberg L, Anderson H, et al.: Breast conservation surgery, with and without radiotherapy, in women with lymph node-negative breast cancer: a randomised clinical trial in a population with access to public mammography screening. Eur J Cancer 2003;39:1690-7.

34 Veronesi U, Marubini E, Mariani L, et al.: Radiotherapy after breast-conserving surgery in small breast carcinoma: long-term results of a randomized trial. Ann Oncol 2001;12:997-1003.

35 Katz A, Buchholz TA, Thames H, et al.: Recursive partitioning analysis of locoregional recurrence patterns following mastectomy: implications for adjuvant irradiation. Int J Radiat Oncol Biol Phys 2001;50:397-403.

36 Katz A, Strom EA, Buchholz TA, et al.: The influence of pathologic tumor characteristics on locoregional recurrence rates following mastectomy. Int $\mathrm{J}$ Radiat Oncol Biol Phys 2001;50:735-42.

37 Patt DA, Goodwin JS, Kuo YF, Freeman JL, Zhang DD, Buchholz TA, Hortobagy GN, Giordano SH: Cardiac morbidity of adjuvant radiotherapy for breast cancer. J Clin Oncol 2005;23:7475-82.

38 Punglia RS, Kuntz KM, Lee JH, et al.: Radiation therapy plus tamoxifen versus tamoxifen alone after breast-conserving surgery in postmenopausal women with stage I breast cancer: a decision analysis. J Clin Oncol 2003;21:2260-7.

39 Rutqvist LE, Rose C, Cavallin-Stahl E: A systematic overview of radiation therapy effects in breast cancer. Acta Oncol 2003;42:532-45.

40 Souchon R: Adjuvant radiotherapy in breast carcinoma. Breast Care 2006;1:259-63.

41 Whelan T: Use of conventional radiotherapy as part of breast-conserving treatment. J Clin Oncol 2005;23:1718-25.

42 Feigenberg SJ, Price Mendenhall N, Benda RK, Morris CG: Postmastectomy radiotherapy: Patterns of recurrence and long-term disease control using electrons. Int J Radiat Oncol Biol Phys 2003;56: 716-25

43 Fisher B, Bryant J, Dignam JJ, et al.: Tamoxifen, radiation therapy, or both for prevention of ipsilateral breast tumor recurrence after lumpectomy in women with invasive breast cancers of one centimeter or less. J Clin Oncol 2002;20:4141-9.

44 Taghian A, Jeong JH, Mamounas E et al.: Patterns of locoregional failure in patients with operable breast cancer treated by mastectomy and adjuvant chemotherapy with or without tamoxifen and without radiotherapy: results from five National Surgical Adjuvant Breast and Bowel Project randomized clinical trials. J Clin Oncol 2004;22:4247-54.

45 de Bock GH, van der Hage JA, Putter H, Bonnema J, Bartelink H, van de Velde CJ: Isolated loco-regional recurrence of breast cancer is more common in young patients and following breast conserving therapy: long-term results of European Organisation for Research and Treatment of Cancer studies. Eur J Cancer 2006;42:351-6. 
46 van Dongen JA, Voogd AC, Fentiman IS, Legrand C, Sylvester RJ, Tong D, van der Schueren E, Helle PA, van Zijl K, Bartelink H: Long-term results of a randomized trial comparing breast-conserving therapy with mastectomy: European Organization for Research and Treatment of Cancer 10801 trial. J Natl Cancer Inst 2000;92:1143-50.

47 Bartelink H, Horiot JC, Poortmans P, Struikmans $\mathrm{H}$, Van den Bogaert W, Barillot I, Fourquet A, Borger J, Jager J, Hoogenraad W, Collette L, Pierart M; European Organization for Research and Treatment of Cancer Radiotherapy and Breast Cancer Groups: Recurrence rates after treatment of breast cancer with standard radiotherapy with or without additional radiation. $\mathrm{N}$ Engl $\mathrm{J}$ Med 2001; 345:1378-87.

-48 Overgaard M, Hansen PS, Overgaard J, Rose C, Andersson M, Bach F, Kjaer M, Gadeberg CC, Mouridsen HT, Jensen MB, Zedeler K: Postoperative radiotherapy in high-risk premenopausal women with breast cancer who receive adjuvant chemotherapy. Danish Breast Cancer Cooperative Group 82b Trial. N Engl J Med 1997;337:949-55.

49 Overgaard M, Jensen MB, Overgaard J, Hansen PS, Rose C, Andersson M, Kamby C, Kjaer M, Gadeberg CC, Rasmussen BB, Blichert-Toft M, Mouridsen HT: Postoperative radiotherapy in high-risk postmenopausal breast-cancer patients given adjuvant tamoxifen: Danish Breast Cancer Cooperative Group DBCG 82c randomised trial. Lancet 1999; 353(9165):1641-8.

50 Ragaz J, Jackson SM, Le N, Plenderleith IH, Spinelli JJ, Basco VE, Wilson KS, Knowling MA, Coppin CM, Paradis M, Coldman AJ, Olivotto IA: Adjuvant radiotherapy and chemotherapy in nodepositive premenopausal women with breast cancer. N Engl J Med 1997;337:956-62.

51 German Cancer Society and AWMF (DE) - Association of Scientific Medical Societies: Quality Assurance in Oncology. Interdisciplinary S3 Guidelines for the Diagnosis and Treatment of Breast Cancer in Women. www.g-i-n.net/download/files/ S3_Diagn_Ther_engl.pdf.

52 Harris JR, Halpin-Murphy P, McNeese M, et al.: Consensus statement on postmastectomy radiation therapy. Int J Radiat Oncol Biol Phys 1999;44: 989-90.

53 Recht A, Edge SB, Solin LJ, et al. for the American Society of Clinical Oncology: Postmastectomy radiotherapy: Clinical practice guidelines of the American Society of Clinical Oncology. J Clin Oncol 2001;19:1539-69.

54 Truong PT, Olivotto IA, Whelan TJ, Levine M, for the Steering Committee on Clinical Practice Guidelines for the Care and Treatment of Breast Cancer: Clinical practice guidelines for the care and treatment of breast cancer: 16. Locoregional post-mastectomy radiotherapy. CMAJ 2004;170:1263-73.

55 Giordano SH, Kuo YF, Freeman JL, Buchholz TA, Hortobagyi GN, Goodwin JS: Risk of cardiac death after adjuvant radiotherapy for breast cancer. J Natl Cancer Inst 2005;97:419-24.

56 Hojris I, Overgaard M, Christensen JJ, Overgaard $\mathrm{J}$ : Morbidity and mortality of ischaemic heart disease in high-risk breast-cancer patients after adjuvant postmastectomy systemic treatment with or without radiotherapy: analysis of DBCG $82 \mathrm{~b}$ and 82c randomised trials. Radiotherapy Committee of the Danish Breast Cancer Cooperative Group. Lancet 1999;354(9188):1425-30.

57 Hall EJ, Wuu CS: Radiation-induced second cancers: the impact of 3D-CRT and IMRT. Int J Radiat Oncol Biol Phys 2003;56:83-8.

58 Huang J, Barbera L, Brouwers M, Browman G, Mackillop WJ: Does delay in starting treatment affect the outcomes of radiotherapy? A systematic review. J Clin Oncol 2003;21:555-63.
Recht A, Come SE, Henderson IC, et al.: The sequencing of chemotherapy and radiation therapy after conservative surgery for early-stage breast cancer. N Engl J Med 1996;334:1356-61.

60 Bellon JR, Come SE, Gelman RS, Henderson IC, Shulman LN, Silver BJ, Harris JR, Recht A: Sequencing of chemotherapy and radiation therapy in early-stage breast cancer: updated results of a prospective randomized trial. J Clin Oncol 2005; 23:1934-40.

61 Sartor CI, Peterson BL, Woolf S, Fitzgerald TJ, Laurie F, Turrisi AJ, Bogart J, Henderson IC, Norton L: Effect of addition of adjuvant paclitaxel on radiotherapy delivery and locoregional control of node-positive breast cancer: cancer and leukemia group B 9344. J Clin Oncol 2005;23:30-40.

62 Fiets WE, van Helvoirt RP, Nortier JW, van der Tweel I, Struikmans H: Acute toxicity of concurrent adjuvant radiotherapy and chemotherapy (CMF or AC) in breast cancer patients. a prospective, comparative, non-randomised study. Eur J Cancer 2003;39:1081-8.

63 Pierce LJ, Hutchins LF, Green SR, et al.: Sequencing of tamoxifen and radiotherapy after breast-conserving surgery in early-stage breast cancer. J Clin Oncol 2005;23:24-9.

64 Schmidberger H, Hermann RM, Hess CF, Emons $\mathrm{G}$ : Interactions between radiation and endocrine therapy in breast cancer. Endocr Relat Cancer 2003;10:375-83.

65 Azria D, Gourgou S, Sozzi WJ, Zouhair A, Mirimanoff RO, Kramar A, Lemanski C, Dubois JB, Romieu G, Pelegrin A, Ozsahin M: Concomitant use of tamoxifen with radiotherapy enhances subcutaneous breast fibrosis in hypersensitive patients. Br J Cancer 2004;91:1251-60.

66 Dörr W, Bertmann S, Herrmann T: Radiation induced lung reactions in breast cancer therapy. Mod ulating factors and consequential effects. Strahlenther Onkol 2005;181:567-73.

67 Baum M, Budzar AU, Cuzick J, Forbes J, Houghton JH, Klijn JG, Sahmoud T; ATAC Trialists' Group: Anastrozole alone or in combination with tamoxifen versus tamoxifen alone for adjuvant treatment of postmenopausal women with early breast cancer: first results of the ATAC randomised trial. Lancet 2002;359(9324):2131-9.

68 Coombes RC, Hall E, Gibson LJ, Paridaens R, Jassem J, Delozier T, Jones SE, Alvarez I, Bertelli G, Ortmann O, Coates AS, Bajetta E, Dodwell D, Coleman RE, Fallowfield LJ, Mickiewicz E, Andersen J, Lonning PE, Cocconi G, Stewart A, Stuart N, Snowdon CF, Carpentieri M, Massimini G, Bliss JM; Intergroup Exemestane Study: A randomized trial of exemestane after two to three years of tamoxifen therapy in postmenopausal women with primary breast cancer. N Engl J Med 2004;350: 1081-92.

69 Goss PE, Ingle JN, Martino S, Robert NJ, Muss HB, Piccart MJ, Castiglione M, Tu D, Shepherd LE, Pritchard KI, Livingston RB, Davidson NE, Norton L, Perez EA, Abrams JS, Therasse P, Palmer MJ, Pater JL: A randomized trial of letrozole in postmenopausal women after five years of tamoxifen therapy for early-stage breast cancer. N Engl J Med 2003;349:1793-802.

70 Joensuu H, Kellokumpu-Lehtinen PL, Bono P, Alanko T, Kataja V, Asola R, Utriainen T, Kokko R, Hemminki A, Tarkkanen M, TurpeenniemiHujanen T, Jyrkkio S, Flander M, Helle L, Ingalsuo S, Johansson K, Jaaskelainen AS, Pajunen M, Rauhala M, Kaleva-Kerola J, Salminen T, Leinonen M, Elomaa I, Isola J; FinHer Study Investigators: Adjuvant docetaxel or vinorelbine with or without trastuzumab for breast cancer. N Engl J Med 2006; 354:809-20.
1 Piccart-Gebhart MJ, Procter M, Leyland-Jones B, Goldhirsch A, Untch M, Smith I, Gianni L, Baselga J, Bell R, Jackisch C, Cameron D, Dowsett M, Barrios $\mathrm{CH}$, Steger $\mathrm{G}$, Huang CS, Andersson M, Inbar M, Lichinitser M, Lang I, Nitz U, Iwata $H$, Thomssen C, Lohrisch C, Suter TM, Ruschoff J, Suto T, Greatorex V, Ward C, Straehle C, McFadden E, Dolci MS, Gelber RD; Herceptin Adjuvant (HERA) Trial Study Team: Trastuzumab after adjuvant chemotherapy in HER2-positive breast cancer. N Engl J Med 2005;353:1659-72.

72 Romond EH, Perez EA, Bryant J, Suman VJ, Geyer CE Jr, Davidson NE, Tan-Chiu E, Martino S, Paik S, Kaufman PA, Swain SM, Pisansky TM Fehrenbacher L, Kutteh LA, Vogel VG, Visscher DW, Yothers G, Jenkins RB, Brown AM, Dakhil SR, Mamounas EP, Lingle WL, Klein PM, Ingle JN, Wolmark N: Trastuzumab plus adjuvant chemotherapy for operable HER2-positive breast cancer. N Engl J Med 2005;353:1673-84.

73 Belkacemi Y, Gligorov J, Laharie-Mineur H, Marsiglia H, Ozsahin M, Azria D: Concurrent administration of weekly trastuzumab and adjuvant breast radiotherapy increases skin, esophageal, and cardiac acute toxicities. J Clin Oncol 2006;24:Supp ASCO Ann Meeting Proc Part I. Vol 24, No 18S, abstr 630

74 Owen JR, Ashton A, Bliss JM, Homewood J, Harper C, Hanson J, Haviland J, Bentzen SM, Yarnold JR: Effect of radiotherapy fraction size on tumour control in patients with early-stage breast cancer after local tumour excision: long-term results of a randomised trial. Lancet Oncol 2006;7: 467-71.

75 Yarnold J, Ashton A, Bliss J, Homewood J, Harper C, Hanson J, Haviland J, Bentzen S, Owen R: Fractionation sensitivity and dose response of late adverse effects in the breast after radiotherapy for early breast cancer: long-term results of a randomised trial. Radiother Oncol 2005;75:9-17.

76 Arthur DW, Vicini FA: Accelerated partial breast irradiation as part of breast conservation therapy. J Clin Oncol 2005;23:1726-35.

77 Johansson S, Svensson H, Larsson LG, Denekamp $\mathrm{J}$ : Brachial plexopathy after postoperative radiotherapy of breast cancer patients - a long-term follow-up. Acta Oncol 2000;39:373-82.

78 Goldhirsch A, Glick JH, Gelber RD, et al.: Meeting highlights: International Consensus Panel on the Treatment of Primary Breast Cancer. Seventh International Conference on Adjuvant Therapy of Primary Breast Cancer. J Clin Oncol 2001;19: 3817-27.

79 Recht A, Gray R, Davidson NE, et al.: Locoregional failure 10 years after mastectomy and adjuvan chemotherapy with or without tamoxifen without irradiation: experience of the Eastern Cooperative Oncology Group. J Clin Oncol 1999;17:1689-700.

80 Clark R, Whelan T, Levine M, et al.: Randomized clinical trial of breast irradiation following lumpectomy and axillary dissection for node-negative breast cancer: an update. J Natl Cancer Inst 1996; 88:1659-64.

81 Holli K, Saaristo R, Isola J, et al.: Lumpectomy with and without postoperative radiotherapy for breast cancer with favourable prognostic features: Results of a randomized study. Br J Cancer 2001; 84:164-9.

82 Liljegren G, Homberg L, Bergh J, et al.: 10-year result after sector resection with or without postoperative radiotherapy for stage I breast cancer: A randomized trial. J Clin Oncol 1999;17:2326-33.

83 Lim M, Bellon JR, Gelman R, Silver B, Recht A Schnitt SJ, Harris JR: A prospective study of conservative surgery without radiation therapy in select patients with stage I breast cancer. Int J Radiat Oncol Biol Phys 2006;65:1149-54. 
84 MacDonald HR, Silverstein MJ, Mabry H, Moorthy B, Ye W, Epstein MS, Holmes D, Silberman H, Lagios M: Local control in ductal carcinoma in situ treated by excision alone: incremental benefit of larger margins. Am J Surg 2005;190:521-5.

85 Macdonald HR, Silverstein MJ, Lee LA, Ye W, Sanghavi P, Holmes DR, Silberman H, Lagios M: Margin width as the sole determinant of local recurrence after breast conservation in patients with ductal carcinoma in situ of the breast. Am J Surg 2006;192:420-2.

86 Omlin A, Amichetti M, Azria D, Azria D, Cole BF, Fourneret P, Poortmans P, Naehrig D, Miller RC, Krengli M, Gutierrez Miguelez C, Morgan D, Goldberg H, Scandolaro L, Gastelblum P, Ozsahin M, Dohr D, Christie D, Oppitz U, Abacioglu U, Gruber G: Boost radiotherapy in young women with ductal carcinoma in situ: a multicentre, retrospective study of the Rare Cancer Network. Lancet Oncol 2006;7:652-6.

87 Wong JS, Kaelin CM, Troyan SL, Gadd MA, Gelman R, Lester SC, Schnitt SJ, Sgroi DC, Silver BJ, Harris JR, Smith BL: Prospective study of wide excision alone for ductal carcinoma in situ of the breast. J Clin Oncol 2006; 24:1031-6.

88 Solin LJ: Is excision alone adequate treatment for low-risk ductal carcinoma-in-situ of the breast? J Clin Oncol 2006;24: 1017-9.

89 Voordeckers M, Van de Steene J, Vinh-Hung V, Storme G: Adjuvant radiotherapy after mastectomy for pT1-pT2 node negative (pN0) breast cancer: is it worth the effort? Radiother Oncol 2003;68: $227-31$

90 Julien JP, Bijker N, Fentiman IS, Peterse JL, Delledonne V, Rouanet P, Avril A, Sylvester R, Mignolet F, Bartelink H, Van Dongen JA: Radiotherapy in breast-conserving treatment for ductal carcinoma in situ: first results of the EORTC randomised phase III trial 10853. EORTC Breast Cancer Cooperative Group and EORTC Radiotherapy Group. Lancet 2000;355(9203):528-33.

91 Schwartz GF, Solin LJ, Olivotto IA, Ernster VL, Pressman PI: Consensus conference on the treat ment of in situ ductal carcinoma of the breast, April 22-25, 1999. Cancer 2000;88:946-54.

92 Silverstein MJ, Lagios MD, Groshen S, Waisman JR, Lewinsky BS, Martino S, Gamagami P, Colburn WJ: The influence of margin width on local contro of ductal carcinoma in situ of the breast. N Engl J Med 1999;340:1455-61.

-93 Sauer R, Budach W, Dunst J, Feyer P, Haase W, Harms W, Sautter-Bihl ML, Souchon R, Wenz R: Leitlinien in der Radioonkologie: Radiotherapie des Mammakarzinom - Version 2005. Strahlenther Onkol 2006;182,(suppl I):1-28.

94 McCormick B: Radiation Therapy Oncology Group: Phase III randomised study of whole breast radiotherapy versus observation with or without optional Tamoxifen in women with good-risk ductal carcinoma in situ of the breast, RTOG-9804, clinical trial. www.rtog.org/qa/98-04/9804.pdf.

95 Bijker N, Meijnen P, Peterse JL, et al.: Breast-conserving treatment with or without radiotherapy in ductal carcinoma-in-situ: ten-year results of European Organisation for Research and Treatment of Cancer randomized phase III trial 10853 - a study by the EORTC Breast Cancer Cooperative Group and EORTC Radiotherapy Group. J Clin Oncol 2006;24:3381-7.

96 Souchon R, Budach W, Dunst J, Feyer P, Haase W, Harms W, Sautter-Bihl ML, Wenz R, Sauer R: Auf eine Radiotherapie nach brusterhaltender Operation eines duktalen Carcinoma in situ (DICS) darf nicht verzichtet werden. Strahlenther Onkol 2006; 182:429-30.
97 Bear HD, Anderson S, Brown A, et al.: National Surgical Adjuvant Breast and Bowel Project Protocol B-27. The effect on tumor response of adding sequential preoperative docetaxel to preoperative doxorubicin and cyclophosphamide: preliminary results from National Surgical Adjuvant Breast and Bowel Project Protocol B-27. J Clin Oncol 2003;21:4165-74.

-98 van der Hage JA, van de Velde CJ, Julien JP, Tubiana-Hulin M, Vandervelden C, Duchateau L: Preoperative chemotherapy in primary operable breast cancer: results from the European Organization for Research and Treatment of Cancer trial 10902. J Clin Oncol 2001;19:4224-37.

99 Chen AM, Meric-Bernstam F, Hunt KK, Thames HD, Oswald MJ, Outlaw ED, Strom EA, McNeese MD, Kuerer HM, Ross MI, Singletary SE, Ames FC, Feig BW, Sahin AA, Perkins GH, Schechter NR, Hortobagyi GN, Buchholz TA: Breast conservation after neoadjuvant chemotherapy: the MD Anderson cancer center experience. J Clin Oncol 2004;22:2303-12.

100 Formenti SC, Volm M, Skinner KA, Spicer D, Cohen D, Perez E, Bettini AC, Groshen S, Gee C, Florentine B, Press M, Danenberg P, Muggia F: Preoperative twice-weekly paclitaxel with concurrent radiation therapy followed by surgery and postoperative doxorubicin-based chemotherapy in locally advanced breast cancer: a phase I/II trial. J Clin Oncol 2003;21:864-70.

101 Garg AK, Strom EA, Mc Neese MD, Buzdar AU, Hortobagyi GN, Kuerer HM, Perkins GH, Singletary SE, Hunt KK, Sahin A, Schechter N, Valero V, Tucker SL, Buchholz TA: T3 disease at presentation or pathological involvement of four or more lymph nodes predict for locoregional recurrence in stage II breast cancer treated with neoadjuvant chemotherapy and mastectomy without radiotherapy. Int J Radiat Oncol Biol Phys 2004;59: 138-45.

102 Gerlach B, Audretsch W, Gogolin F, Konigshausen T, Rohn R, Schmitt G, Dimmerling P, Gripp S, Hartmann KA: Remission rates in breast cancer treated with preoperative chemotherapy and radiotherapy. Strahlenther Onkol 2003;179: 306-11.

103 Lerouge D, Touboul E, Lefranc JP, Genestie C, Moureau-Zabotto L, Blondon J: Combined chemotherapy and preoperative irradiation for locally advanced noninflammatory breast cancer: updated results in a series of 120 patients. Int $\mathbf{J}$ Radiat Oncol Biol Phys 2004;59:1062-73.

104 Shenkier T, Weir L, Levine M, Olivotto I, Whelan T, Reyno L; Steering Committee on Clinical Practice Guidelines for the Care and Treatment of Breast Cancer: Clinical practice guidelines for the care and treatment of breast cancer: 15 . Treatment for women with stage III or locally advanced breast cancer. CMAJ 2004;170:983-94.

105 Ring A, Webb A, Ashley S, Allum WH, Ebbs S, Gui G, Sacks NP, Walsh G, Smith IE: Is surgery necessary after complete clinical remission following neoadjuvant chemotherapy for early breast cancer? J Clin Oncol 2003;21:4540-5.

106 Souchon R, Dunst J, Hartmann KA: Radiotherapie im Konzept der primären («neoadjuvanten») systemischen Behandlung des Mammakarzinoms. Strahlenther Onkol 2006;182:202-9.

107 Mauri D, Pavlidis N, Ioannidis JP: Neoadjuvant versus adjuvant systemic treatment in breast cancer: a meta-analysis. J Natl Cancer Inst 2005;97: 188-94.
108 Chen AM, Meric-Bernstam F, Hunt KK, Thames HD, Outlaw ED, Strom EA, McNeese MD, Kuerer HM, Ross MI, Singletary SE, Ames FC, Feig BW, Sahin AA, Perkins GH, Babiera G, Hortobagyi GN, Buchholz TA: Breast conservation after neoadjuvant chemotherapy. Cancer 2005; 103:689-95.

109 Chawla AK, Kachnic LA, Taghian AG, Niemierko A, Zapton DT, Powell SN: Radiotherapy and breast reconstruction: Complications and cosmesis with TRAM versus tissue expander/implant. Int J Radiat Oncol Biol Phys 2002;54:520-6.

110 Kroll SS, Schusterman MA, Reece GP, Miller MJ, Smith B: Breast reconstruction with myocutaneous flaps in previously irradiated patients. Plast Reconstr Surg 1994;93:460-9.

111 Kronowitz SJ, Robb GL: Breast reconstruction with postmastectomy radiation therapy: current issues. Plast Reconstr Surg 2004;114:950-60.

112 Krueger EA, Wilkins EG, Strawderman M, Cederna P, Goldfarb S, Vicini FA, Pierce LJ: Complications and patients satisfaction following expander/implant breast reconstruction with and without radiotherapy. Int $\mathrm{J}$ Radiat Oncol Biol Phys 2001;49:713-21.

113 Tallet AV, Salem N, Moutardier V, Ananian P, Braud A-C, Zalta R, Cowen D, Houvenaeghel G: Radiotherapy and immediate two-stage breast reconstruction with a tissue expander and implant: complications and esthetic results. Int $\mathbf{J}$ Radiat Oncol Biol Phys 2003;57:136-42.

114 Kronowitz SJ, Feledy JA, Hunt KK, Kuerer HM, Youssef A, Koutz CA, Robb GL: Determining the optimal approach to breast reconstruction after partial mastectomy. Plast Reconstr Surg 2006;117:1-11

115 Tran NV, Chang DW, Gupta A, Kroll SS, Robb GL: Comparison of delayed free TRAM flap and breast reconstruction in patients receiving postmastectomy radiation therapy. Plast Reconstr Surg 2001;108:78-82.

116 Contant CM, van Geel AN, van der Holt B, Griep C, Tjong Joe Wai R, Wiggers T: Morbidity of immediate breast reconstruction (IBR) after mastectomy by a subpectorally placed silicone prosthesis: the adverse effect of radiotherapy. Eur J Surg Oncol 2000;26:344-50.

117 Forman DL, Chiu J, Restifo RJ, Ward BA, Haffty B, Aiyan S: Breast reconstruction in previously irradiated patients using tissue expanders and implants: a potentially unfavourable result. Ann Plast Surg 1998;40:360-4.

118 Victor SJ, Brown DM, Horwitz EM, Martinez AA, Kini VR, Pettinga JE, Shaheen KW, Benitez P, Chen PY, Vicini FA: Treatment outcome with radiation therapy after breast augmentation or reconstruction in patients with primary breast carcinoma. Cancer 1998;83:1303-9.

119 Motwani SB, Strom EA, Schechter NR, Butler CE, Lee GK, Langstein HN, Kronowitz SJ, MericBernstam F, Ibrahim NK, Buchholz TA: The impact of immediate breast reconstruction on the technical delivery of postmastectomy radiotherapy. Int J Radiat Oncol Biol Phys 2006;66:76-82.

120 van Asselen B, Schwarz M, van Vliet-Vroegindeweij C, Lebesque JV, Mijnheer BJ, Damen EM: Intensity-modulated radiotherapy of breast cancer using direct aperture optimization. Radiother Oncol 2006;79:162-9.

121 Bentzen SM: Theragnostic imaging for radiation oncology: dose-painting by numbers. Lancet Oncol 20005;6:112-7.

122 Bentzen SM: Radiation therapy: intensity modulated, image guided, biologically optimized and evidence based. Radiother Oncol 2005;77:227-30. 